\begin{tabular}{lcl}
\hline Bentham OPEN & The Open PSychology Journal \\
CrossMark & Content list available at: www.benthamopen.com/TOPSYJ/ & DOI: $10.2174 / 1874350101710010011$ \\
\hline Open Psychology
\end{tabular}

RESEARCH ARTICLE

\title{
Time Perspective and the Psychological Well-Being of Chinese University Students adapting to Russia
}

\author{
Tatiana S. Pilishvili
}

Department of Psychology and Pedagogic, Peoples' Friendship University of Russia (RUDN University), Moscow, Russia

\section{Abstract:}

Background:

The purpose is to examine the specifics of time perspective and the psychological well-being of Chinese University students, who differ in their level of social-psychological adaptation to Russia.

\section{Objective:}

The psychological well-being and time perspective.

\section{Method:}

With the use of 5 questionnaire-type methodologies we conducted the study with 120 RUDN University students (60 men and 60 women from China).

\section{Results:}

The comparative and factor analysis reveal that there are differences in time perspective and psychological well-being. Students from the 1st group, who have been in Russia for less than one year, have adapted the least to Russian culture. They experience a low level of subjective well-being. The 2 nd with approximately 3 years of adapting to a new culture shows instability in adapting. Their level of self-acceptance is average; they often experience emotional discomfort. The 3rd group with more than 5 years of immersion into a new culture, demonstrates a higher level of adaptation as well as a higher level of subjective well-being. This group is able to identify the positive experiences from their past and can relate to the uncertainty of their future optimistically. A link was found between maladaptation in the context of poor time perceptive, a negative view of one's self in the past and the inability to intrinsically control ones present. The results received cohere with the concept of adaptation as a cyclical ever-increasing curve Y.Y. Kim.

\section{Conclusion:}

The observed differences can help to develop a program dedicated to the psychological adaptation of foreign students in Russia.

Keywords: Adaptation to Russia, Chinese international students, Emotional comfort, Psychological well-being, Social-psychological adaptation, Time perspective.

\section{INTRODUCTION}

Education in Modern universities is closely connected with students' high academic mobility [1]. Chinese students frequently pursue an education in Russia to learn a foreign language as well as to obtain multicultural competences [2]. Adapting to a new culture is often a rather stressful stage in the students' life where homesickness often leads to living

\footnotetext{
* Address correspondence to this author at the Department of Psychology and Pedagogic, Peoples' Friendship University of Russia (RUDN
} University), Moscow, Russia; Tel: 84957873803; Email: pilishvili_ts@pfur.ru 
in the past, lack of interest in the present, which results in an undesired future. Chinese students experiencing communication difficulties in a new multicultural environment are being excluded from the "here and now" process, as it reduces feelings of emotional discomfort. For this reason, it is necessary to study time perspective and psychological well-being among University students at various stages of social-psychological adaptation in order to improve their quality of life during their sojourn in a foreign country.

\section{THEORETICAL REVIEW}

Social psychology of time concerns the study of intrapersonal, cross-cultural resources. This study is focused more specially on realizing an active lifestyle dedicated to the development of the individual. In adapting to another culture, an individual's balanced time perspective shows that life's journey is being perceived through the individual's past present - future [3]. Emphasis should be placed on the fact that Chinese students in Russia do not often possess that level of expectation along social and professional lines. This is associated with a lack of perspective [4, p. 144]. Studies also reveal a correlation between the need to relax and the subjective compactness of time [5]; the possibility to improve one's present depressive state during the stressful moments of acculturation [6]; the association between how the cultural group from China manages their present life and success in studying abroad in western universities [7].

Coming from an integral socio-psychological education [8], subjective well-being is conceptualized as a chain of feedbacks within a system of the person's active take on life [9]. This connects to a value system, which provides internal satisfaction allowing for a few permitted discrepancies between one's expectations and the process of adapting by keeping a positive outlook on the occurrences around him [10]. The adolescence age is considered as one of the normative crisis during the development period of the individual [11]. These resources become the aim of the person to "support a relatively high and stable subjective well-being" [12, p. 17]. In this case, the Chinese students studying in Russian universities are adapting to the stress of acculturation [13], which requires a different strategy of coping than is usually accepted in their culture [14]. In studying subjective well-being among Chinese students, it was found that the level of their accessibility, the extent of their disassociation, their internal conflict and internal vacuum are the leading factors and not results showing "the level of subjective well-being" [15, p. 100]. The study showed that new cultural contexts could be presented as both a positive and a negative indication of the subjective well-being of an individual coming from a society of ethnic minorities [16]. Depending on the stage of adaptation, the individual's level of subjective well-being can range from euphoria to complete disappointment in the new culture. According to the different authors, these changes are linked to the U-curve adjustment by H. Triandis [17], W-curve adjustment by J.T. Gullahorn \& J.E. Gullahorn [18], the combination of U and W curves by S. Bochner, A. Lin, B.M. McLeod [19], cyclical curve "two-steps-forward-one step back" by Y.Y. Kim [20].

There is a necessity to study the different variants of the adjustment activities of the individual [21] and their link to time perspective and subjective well-being, which is stipulated by inter-scientific reasons [22], as well as the necessity for growth in the quality of life for international students hailing from different countries [23]. The objective of this research is to study time perspective and subjective well-being of Chinese students in RUDN who are on different levels of adapting to a foreign culture. This study will test for the aforementioned concepts of adaptation as a varying process. The hypothesis proposed in this study was as follows: time perspective and subjective well-being change with the growth of Chinese students' adaptation to Russia.

\section{METHOD}

\section{Participants}

A sample of 120 participants was collected, 60 men and 60 women from China; age range: $18-25$ years, $\mathrm{M}=22$, SD $=3.67$ was selected from RUDN University Bachelor's and Master's students (philological, medical and socialhumanities departments). The first sample consisted of 40 students pursuing a bachelor's degree who are currently in the preparatory faculty, 20 men and 20 women with less than one year of adapting to Russia; the second sample includes 40 second year students pursuing a bachelor's degree, 20 men and 20 women (with approximately three years of adaptation to Russia); the third sample - of 40 second year Bachelor's students, 20 men and 20 women (with more than five years of adaptation to Russia). Students were put into three groups based on their language skills, but more specifically, based on their skills in Russian language. This parameter was based on their socio-psychological aspects of adaptation, which is a necessary parameter, however it does not consider the adaptiveness of their personalities. Students with high grades in subjects related to their major and also having high levels of acceptance towards the university and the country were preliminarily chosen. In the questionnaire, all of the students answered that they came 
to Russia by their own decision for the purpose of studying at this university, and that they plan to return to China after receiving a Master's degree (giving them a maximum of 7 years of studying). The general selection of students was set by their experience in acculturation. All of the students had never studied overseas, making this their first time travelling to another country for the purpose of education. None of the students studied Russian before, however all of them have an intermediate level of English. The students are monolinguals due to the fact that at home in China they solely spoke in Chinese. They were also divided equally by age and gender within the three groups.

\section{Instruments}

The participants were asked to answer the following Chinese adapted self-report questionnaires.

The Zimbardo Time Perspective Inventory, Zimbardo and Boyd [24] is a 56-item measure consisting of five subscales (past-negative, past-positive, present-fatalistic, present-hedonistic, future time perspective), each including 9-15 items. Participants respond to statements using a 7-point Likert scale.

The Ambiguity Tolerance scale, D.L. Mcclain [25] is a 22-item measure consisting of six subscales (attitude to novelty; attitude to complex tasks; attitude to uncertain situations; favorites uncertainty; tolerance to uncertainty; overall score). Participants respond to statements using a 5-point Likert scale.

The C. Ryff Scales of Psychological Well-Being [26]. The questionnaire consists of 6 dimensions: autonomy, environmental mastery, personal growth, positive relations with others, purpose in life, self-acceptance. Individuals respond to various statements and indicate on a 6-point Likert scale how true each statement is. Higher scores on each on scale indicate greater well-being on that dimension.

The E. Diener Satisfaction With Life Scale [27]. The SWLS is a short 5-item instrument designed to measure global cognitive judgments of satisfaction with one's life. Individuals respond to various statements and indicate on a 7-point Likert scale how true each statement is of them.

The C.R. Rogers \& R.F. Dymond Scales of social-psychological adaptation [28]. The questionnaire consists of 6 dimensions with their positive and negative poles: adaptation, acceptance of others, internality, self-perception, emotional comfort, the desire to dominate. Individuals respond to various statements and indicate on a 7-point Likert scale how true each statement is of them.

\section{Procedure}

All of the respondents who took part in the research were invited to the psychological support center at RUDN University and individually filled out questionnaires in the order mentioned above. On average, the questionnaires were completed in 30 minutes. All of the questionnaires used were double translated (from English to Chinese and again to English), Chinese adapted and met the requirements for validity. To process the obtained data Kruskal-Wallis $\mathrm{H}-$ test, trend test, factorial analysis (Varimax foundation) were used. The calculations were done using the SPSS 22.0 computer program.

\section{RESULTS}

\section{Comparisons Among Groups}

In order to measure the possible gender differences within the Chinese student groups the Mann-Whitney U - test was utilized. It was shown that there are not significant differences within the three groups or within the convenient sample.

The comparative analysis of three Chinese students' groups in connection with their adaptation to Russia stage by Kruskal-Wallis $\mathrm{H}$ - test showed that there were significant differences on past-positive $\left(\mathrm{X}^{2}=51.6 ; \mathrm{p}=0,001 ; \mathrm{MR} 1=\right.$ 29.48; MR $2=69.29$; MR $3=82.75)$; past-negative $\left(\mathrm{X}^{2}=75.5 ; \mathrm{p}=0,001\right.$; MR $1=82.74$; MR $2=76.91$; MR $3=$ 22.85); future time perspective $\left(X^{2}=103.5 ; \mathrm{p}=0,001 ; \mathrm{MR} 1=20.93\right.$; MR $2=60.66$; MR $\left.3=99.91\right)$; present-fatalistic $\left(X^{2}=100.1 ; p=0,001 ;\right.$ MR $1=98,51 ;$ MR $2=62,34 ;$ MR $\left.3=20,65\right)$; present-hedonistic, $\left(X^{2}=105,6 ; p=0,001 ;\right.$ MR 1 $=100,5 ;$ MR $2=60,48 ;$ MR $3=20,53)$; tolerance to uncertainty $\left(X^{2}=105,9 ; p=0,001 ; \operatorname{MR} 1=19,95 ;\right.$ MR $2=58,5$; MR $3=100,6)$.

There were significant differences in the overall psychological well-being scales $\left(X^{2}=105,9 ; p=0,001 ; M R 1=\right.$ $21,61 ; \operatorname{MR} 2=62,49$; MR $3=101,3)$; satisfaction with daily activities $\left(\mathrm{X}^{2}=106,7 ; \mathrm{p}=0,001 ; \mathrm{MR} 1=19,89\right.$; MR $2=$ 
63,36; MR $3=102,0)$; health self-esteem $\left(X^{2}=104,2 ; \mathrm{p}=0,001 ; \mathrm{MR} 1=18,76 ; \mathrm{MR} 2=59,97 ; \mathrm{MR} 3=103,1\right)$; importance of the social environment $\left(X^{2}=101,9 ; p=0,001\right.$; MR $1=22,09$; MR $2=58,51$; MR $\left.3=99,5\right)$; positive relations with others $\left(X^{2}=83,7 ; p=0,001\right.$; MR $1=33,47$; MR $2=47,8$; MR $\left.3=100,5\right)$; autonomy $\left(X^{2}=102,4 ; p=\right.$ $0,001$; MR $1=20,85$; MR $2=61,43$; MR $3=99,23)$; environmental mastery $\left(X^{2}=106,1 ; p=0,001 ;\right.$ MR $1=20,54$; MR $2=60,46 ;$ MR $3=98,5)$; personal growth $\left(X^{2}=106,1 ; p=0,001 ; \operatorname{MR} 1=22,54 ;\right.$ MR $2=64,18 ;$ MR $\left.3=102,09\right)$; purpose in life $\left(\mathrm{X}^{2}=100,1 ; \mathrm{p}=0,001 ; \mathrm{MR} 1=18,89\right.$; MR $2=61,25 ;$ MR $\left.3=98,33\right)$.

The comparative analysis of the three groups of Chinese students in connection with their adaptation to Russia stage by Kruskal-Wallis $\mathrm{H}$ - test showed that there were significant differences on adaptation $\left(\mathrm{X}^{2}=105,8 ; \mathrm{p}=0,001 ; \mathrm{MR} 1=\right.$ 20,5; MR $2=60,5$; MR $3=100,5)$; self-perception $\left(X^{2}=105,4 ; p=0,001 ;\right.$ MR $1=20,53 ;$ MR $2=60,71 ;$ MR $3=$ $100,26)$; acceptance of others $\left(X^{2}=98,0 ; p=0,001\right.$; MR $1=20,61$; MR $2=63,69$; MR $\left.3=97,20\right)$; emotional comfort $\left(X^{2}=85,2 ; p=0,001 ;\right.$ MR $1=29,04 ;$ MR $2=53,23$; MR $\left.3=99,24\right)$; internality $\left(X^{2}=106,1 ; p=0,001 ; M R 1=21,31\right.$; MR $2=65,15 ;$ MR $3=95,04)$; the desire to dominate $\left(X^{2}=91,5 ; p=0,001 ;\right.$ MR $1=20,51 ;$ MR $2=61,5 ;$ MR $3=$ $100,49)$.

The one-way ANOVA was conducted to compare the effect of the adaptation period over time and the psychological well-being of the Chinese university students. The preliminary Test of Homogeneity of Variances showed that the homogeneity within the groups (and therefore sufficient for ANOVA) were the following scales: pastnegative $(\mathrm{p}=0,553)$; self-perception $(\mathrm{p}=0,962)$; adaptation $(\mathrm{p}=0,335)$; acceptance of others $(\mathrm{p}=0,851)$; emotional comfort $(p=0,931)$; internality $(p=0,097)$; health self-esteem $(p=0,352)$; positive relations with others $(p=0,066)$; autonomy $(\mathrm{p}=0,283)$; psychological well-being in general $(\mathrm{p}=0,373)$; personal growth $(\mathrm{p}=0,384)$. There was a significant effect of adaptation period for the past-negative $(F=137,7 ; p=0,001)$; adaptation $(F=1070,5 ; p=0,001)$; self-perception $(F=668,5 ; p=0,001)$; acceptance of others $(F=442,6 ; p=0,001)$; emotional comfort $(F=135,4 ; p=$ $0,001)$; internality $(F=212,5 ; p=0,001)$; health self-esteem $(F=396,7 ; p=0,001)$; positive relations with others $(F$ $=445,6 ; p=0,001)$; autonomy $(F=435,5 ; p=0,001)$; psychological well-being in general $(F=4219,6 ; p=0,001)$; personal growth $(\mathrm{F}=1548,3 ; \mathrm{p}=0,001)$. Post hoc comparisons using the Tukey HSD test indicated that there are significant differences between the students of all three groups by the following scales: self-perception; acceptance of others; emotional comfort; internality; health self-esteem; positive relations with others; autonomy; psychological wellbeing in general; personal growth. By the Past-negative scale the differences between the first group with the most least time of adaptation and the other two groups were observed. The latter two groups did not have significant differences in mean. Thus, a decreasing trend depending on the period of adaptation up to three years and another of more than three years was observed on the past-negative scale. There was also an increasing trend from one group to another among the scales regarding self-perception; acceptance of others; emotional comfort; internality; health self-esteem; positive relations with others; autonomy; psychological well-being in general; personal growth.

\section{Factor Analysis}

Factorial analysis using the rotation Varimax allowed for 3 factors to be highlighted among the respondents who have been at the adaptive stage for less than a year. The first factor explains $47 \%$ of depression and includes the following variables: adaptation $(0,930)$; internality $(0,806)$; coping with one's surroundings $(0,712)$; autonomy $(0,668)$; indications that lead to the main psycho-emotional symptomology $(0,665)$; emotional comfort $(0,609)$. This factor was referred to as the psycho-emotional symptomology of adaptation within the context of the autonomic management of one's surroundings. The second factor reflects $38 \%$ of depression and consists of the following variables: maladaptation $(0,803)$ self-acceptance $(0,759)$. This factor was called maladaptation (self-refusal). The third factor shows $10 \%$ of depression and consists of the internal control variable. $(0,711)$; tolerance towards uncertainty $(-0,670)$. This factor was given the name internal control in regards to low tolerance towards uncertainty.

The first factor from the group of Chinese students who have been going through the adaptive process for approximately three years explains $43 \%$ of depression and consists of present-fatalistic $(0,819)$; life goals $(0,784)$; coping with one's surroundings $(0,775)$; externality $(0,721)$; Stress and sensitivity $(-0,703)$; personal development $(0,680)$; Self-acceptance $(0,674)$; maladaptation $(0,671)$; present-hedonistic $(0,662)$; emotional discomfort $(0,651)$ This factor was referred to as maladjustment relative to one's fatalistic and hedonistic present outlook on life with selfacceptance and attempts for personal development by possessing control over one's surroundings. The second factor brings to light $26 \%$ of depression and includes the following variables: adaptation $(0,956)$; internality $(0,887)$; emotional comfort $(0,740)$. This factor was expressed as adaptation with internal and emotional comfort. The third factor highlights $19 \%$ of depression and utilized the following variables: escapism $(0,712)$; past-positive $(0,669)$; 
maladaptation $(0,650)$. The above factor was given the name maladaptation due to the absence of a positive past.

The first factor in reference to the Chinese group of students who have been coping with the adaptive process for more than 5 years explains $37 \%$ of depression and includes the following variables: adaptation $(0,900)$; internality $(0,727)$; accepting others $(0,693)$; tolerance to uncertainty $(0,692)$; self-acceptance $(0,663)$; emotional comfort $(0,653)$. This factor was called emotionally comfortable adjustment with a focus on self-acceptance, acceptance of others and accepting uncertainty for the future. $23 \%$ of depression was given to the second factor. The following variables were included in this factor: Indications for the main psycho-emotional symptomology $(0,781)$; internality $(0,736)$; maladaptation $(0,735)$; acceptance of others $(0,718)$; emotional discomfort $(0,694)$; past-positive $(-0,678)$; negative selfperception $(0,670)$. This factor was called maladaptation based on negative psycho-emotional symptomology and selfacceptance with internalization and a positive relation to the past. The third factor shows $19 \%$ of depression and includes the following variables: The degree of satisfaction in daily activities $(0,751)$; a tendency to follow or relinquish control $(-0,746)$; present-hedonistic $(-0,742)$; quality of health $(0,701)$; satisfaction with life $(0,659)$; future time perspective $(0,698)$. This factor was referred to as satisfaction in one's present life with a high level of independence in future time perspective.

\section{DISCUSSION}

The results of the study support our hypotheses: the improvement of time perspective and subjective correlates with the state of the Chinese students' adaptation to Russia. Among the groups with less than three years of adaptation period, a stable decrease in negative evaluations of the past can be observed. It could be that this period signifies the passage of a potential crisis during adaptation and the reevaluations of events in live. It could also be compared with problems related to aging, which undoubtedly requires deeper research. A stable increase was observed from group to group in adaptation, self-perception, acceptance of others, emotional comfort, internality, health self-esteem, positive relations with others, autonomy, personal growth, psychological well-being in general.

The results from the comparative study suggests that during the first year of adaptation, students are not focused on the past or the future. Their satisfaction and joy is targeted at the present, which is conceptualized as fatalistic, unpredictable, and independent of themselves. This group of students are considered the most maladjusted; these students have problems with accepting themselves and others. Due to this state of emotional disbalance, the students become followers and cling to the hope of being led by their surroundings instead of taking charge themselves. This group of students often express a desire to avoid unpredictable situations that may lead to better adaptation. Regarding the group of students who have been adapting to Russian culture for over 5 years, it can be seen that they are more adapted because of how they meet the requirements of Russian culture. This group relates to their future with more positivity and to a lesser extent, focus both their positive and negative past experiences on obtaining satisfaction in the present. This group is more prone to accepting themselves and others; they are more emotionally animated with positive emotions, they wield a higher level of internal control in their life events. These students prefer to be in charge as opposed to being led by others and are very tolerant towards uncertainties in their future.

The group of students living in a foreign country for approximately 3 years see their past in a negative light, they are more focused on their past than they are on their future. Their present is not as hedonistic as it is fatalistic. The degree of adaptation in this group of respondents is average. This group accepts others more than they accept themselves. Their emotional dissonance is most likely a result of their level of internal control and desire to dominate and to be in control of their lives. This group's level of avoiding undesirable situations is as high as the group with less than one year of adapting to a new culture. This group is more patient towards the uncertainty of their future.

Based on the comparative study, the general subjective well-being of Chinese students improves when the students are more adapted to Russian institutions of higher learning. Moreover, respondents with less than one year of experience in adjusting to a foreign culture has the lowest marker in how they subjectively view their own health. This group gets the least satisfaction from their daily activities and regards their social surroundings as insignificant. This group also has the least control over their environment; they experience maladjustment due to a lack of personal growth and they struggle in accepting themselves and others. In addition, this group experiences emotional discomfort when living without defined goals and objectives. This Chinese group does not aspire to be in control of their lives, rather they prefer to be followers. In addition, this group often avoids difficulties, choosing instead symbolic realities. This reaction is more typical of this group in comparison to the other two groups.

Chinese students who have been adapting to a foreign culture for approximately three years differ in that they are 
able to accept others but face difficulty in accepting themselves. At this stage, the students are still experiencing emotional discomfort due to instability in adjusting to a new culture. This group of respondents experience internal control of the situations occurring around them. They prefer to play a leading role in their lives, as opposed to following the dictates of others idea of how one should live. Autonomy is average in this group. Escapism in making choices is also average due to the presence of personal growth and life goals. The level of satisfaction gained from every-day tasks is median. This group of Chinese students are more prone to having control over activities that surround them; however, the degree to which their relationships with others are positive is similar to that of the first group of respondents.

Chinese students who have been experiencing adjustment to another culture for more than five years have a better subjective perception of their own health. This group is largely satisfied with the events in their day-to-day transactions; they view their social surroundings as positive and significant. This group of respondents manages the events occurring within their surroundings well, they adjust well due to their personal growth and by accepting themselves and others. They are emotionally content because they possess life goals. This group of Chinese students aspirers to be the author of their choices. As a result, this group has a high level of subjective well-being and is prone to seek escapism on a much smaller scale than the other two groups.

The results from the factorial analysis show that based on the adaptive level of the Chinese students to another culture, similarities and differences in time perspective can be found. Factors that may threaten successful adaptation include the link between maladjustment and low tolerance to uncertainty i.e. low time perspective in regards to the future; the inability to control one's present life, which is perceived as alienated and independent of the individual; refusal to accept negative past experiences as valuable lessons. The following are resources that entail time perspective relative to adaptation: tolerance towards uncertainty, such as being open to one's future and internal control of the present, which brings satisfaction. This concurs with earlier studies that link positive time perspective and conscious self-regulation when studying in higher learning institutions [29], and acceptance the positive past.

Based on the results from the factorial analysis obtained from studying the groups of Chinese students, mention can be made of three groups of factors that explain adaptation to a new culture. The following factors have been outlined for the group of students who have been in the adaptive process for less than one year: a) psycho-emotional symptomology of adaption with autonomy in controlling one's surrounding; b) maladaptation due to incapability of accepting one's self; c) internal control during low tolerance towards uncertainty. The results revealed that the group with less than one year of experience in adapting to another culture is prone to adapt with the presence of negative emotions and internal control, autonomy, unacceptance of self and a low level of openness towards one's uncertain future. Despite this, there are prerequisites to maladjustment, which points to instability in the process of adaptation.

The group that has been adapting to another culture for approximately three years is outlined by the following factors: a) maladjustment due to a fatalistic and hedonistic present that is linked to not accepting one's self and attempts for personal growth by controlling one's surroundings; b) adaptation with internality and emotional comfort; c) maladaptation due to the lack of a positive past. The results means that the adaptability of the Chinese respondents utilizes internal control and emotional relaxation. However, it is important to mention that maladaptation is found in the abandoning of reality within one's positive past.

The following factors were outlined for the group consisting of students who have been adapting to another culture for more than five years: a) adapting is an emotionally comfortable process where they accept themselves, others and also the uncertainty that their future brings; b) maladjustment takes place due to negative psycho-emotional symptomology and self-rejection as well as a positive view of the past; c) satisfaction of one's present due to high levels of independence and future time perspective. The results show that adaptation of the Chinese students is made possible because of internal control and by accepting themselves as well as others. A subjective contentment with one's health as well as satisfaction in one's daily events are also attributed to factors that aid in the adaptation of the Chinese students. At this stage, maladaptation is connected to a negative psycho-emotional symptomology with a connection to selfrejection.

Some study limitations merit comment. It would have been desirable to include more participants. The correlational nature of the study forbids making causal inferences. There is a requirement for additional psychological studies that focus on time perspective and the psychological well-being among Chinese University students on different stages of adaptation to Russia and other countries. The comparative study of how Chinese students adapt to the different countries would aid in understanding the universal and specific characteristics of time perspective and the psychological well-being among Chinese University students at different stages of adaptation. Future research efforts are needed to 
overcome these limitations in order to provide a better understanding of adaptation as a psychological process that is connected to measurements of time perspective as well as results that are conveyed in the subjective satisfaction and general psychological well-being of the individual.

\section{CONCLUSION}

Based on this study the author was able to validate the hypothesis concerning the increase of subjective well-being among Chinese students studying in RUDN. A process is seen from a low level of contentment with one's self and one's surroundings of those with less than one year of adapting, to the group with over five years of adapting which can control its surroundings and experience satisfaction in day-to-day occurrences. These results concur with concepts of adaptation that were mentioned earlier such as cyclical curve by Y.Y. Kim [20]. There are differences in the level of subjective well-being of the three groups that were studied a) the absence or availability of life-goals, personal development, autonomy; b) the perception held of one's self and others c) the ability to control one's surroundings, to lead or to follow; d) the constant state of preparedness to actively manage the events that occur in one's life or the choice of escaping into a symbolic reality. The Factorial structures of the group of respondents that show the connection between adaptation and internal control of the three groups were outlined: the link between maladjustment and escapism among respondents who have been adapting for approximately three years. The correlation between the subjective well-being on later stages of adaptation with a high level of independence, control of one's surroundings and taking a leading role in one's life choices validate the importance of taking an active role and leading out when adjusting to a new culture [30].

The result of the present study will be used in the psychological support center in RUDN University. The results will be utilized in individual as well as in group consultations for Chinese students to allow for a more effective adaptive process by incorporating time perspective with regards to the past and the future. The reevaluation of one's negative view of the past by utilizing conscious effort and by tapping into one's subjective well-being in the present will also aid Chinese students in effectively adapting to a new culture.

\section{ETHICS APPROVAL AND CONSENT TO PARTICIPATE}

Not applicable.

\section{HUMAN AND ANIMAL RIGHTS}

No Animals/Humans were used for studies that are base of this research.

\section{CONSENT FOR PUBLICATION}

Not applicable.

\section{CONFLICT OF INTEREST}

The author confirms that this article content has no conflict of interest.

\section{ACKNOWLEDGEMENTS}

The study has been supported by departments of grant initiative projects (RUDN University), the project № 051316-0-000 “Students' ethno-cultural values and students' motivational setups in the internationally-oriented university". The author extends thanks to all the students who participated, as well as to Thomas Jhonaton, (RUDN University) for technical assistance, Huang Lu (Master in psychological counseling, RUDN University), Pan Jie (Master in psychological counseling, RUDN University) for empirical data gathering.

\section{REFERENCES}

[1] Pashby K, Andreotti V. Ethical internationalisation in higher education: interfaces with international development and sustainability. Environ Educ Res 2016; 22: 771-87.

[http://dx.doi.org/10.1080/13504622.2016.1201789]

[2] Kosheleva EY, Samofalova EI, Holtman C, Kopotilova YE. Chinese Students in Russia: Causes of Migration and Basic Educational Behavioral Tenets, IECC 2015 In: Fell E, Ed. Conference Proceedings. 38-42.

[3] Nestik TA. Social psychology of time: actual state and prospects of researches. Psikholog Zh 2014; 35(3): 5-19.

[4] Knyazeva AG. Features and Chinese students adaptation factors to the Russian-speaking information space. Bulletin of the Novosibirsk State 
University. Pedagogy 2013; 14(1): 142-6.

[5] Jiang D, Fung H, Sims T, Tsai JL, Zhang F. Limited time perspective increases the value of calm. Emotion 2016; 16(1): 52-62. [http://dx.doi.org/10.1037/emo0000094]

[6] Wei M, Heppner P, Mallen M. Acculturative stress, perfectionism, years in the United States, and depression among Chinese international students. J Counsel Psychol 2007; 54(4): 385-94 [http://dx.doi.org/10.1037/0022-0167.54.4.385]

[7] Zhang D, ven Bearbeitet D. The situation of Chinese students in Germany. Germany: Herbert Ut3 Verlay 2015.

[8] Shamionov RM. Some transformations of subjective well-being of the individual structures in different conditions of professional socialization. World Psychol 2010; 1: 237-49.

[9] Dzhidaryan IA, Antonova E. The problem of general life satisfaction. heoretical and Empirical Study of Consciousness Identity crisis in society Moscow: Publishing House of the "Institute of Psychology, Russian Academy of Sciences" 1995; 76-93.

[10] Yaremchuk SV. Subjective well-being as a component of value-semantic sphere of the person. Psychol J 2013; 34(5): 85-95.

[11] Kashchuk YN. Experience of life meaning crisis in adolescence. Educ Sci 2011; 6: 52-60.

[12] Benko EV. Subjective welfare regulations in the dynamics of identity crises. In: Bogoyavlenskaya DB, Ed. From the beginning to the present: 130 years of the organization of Psychological Society at Moscow University. 2015; pp. 16-8.

[13] Samsonova MS. Coping strategies at the cultural adaptation process. Psychol Sci Educ 2013; 4: 222-9.

[14] Lykova NM. Overcoming the acculturation stress by Latino and Chinese students. Bulletin of Peoples' Friendship University of Russia University. Psychol Pedagog 2011; 1: 30-6.

[15] Kocharian AS, Makarenko AA, Xiaolong V. Value-availability in different spheres of Chinese students life. In: Prospects of science and education. 2015; 1: pp. (13)96-100.

[16] Usova NV. The cultural context and personal subjective well-being. Basin Res 2014; 9(12): $2784-7$.

[17] Triandis HC. Culture and social behavior New York: McGraw-Hill 1994

[18] Gullahorn JT, Gullahorn JE. An extension of the U-curve hypothesis. J Soc Issues 1963; 19(3): 33-47. [http://dx.doi.org/10.1111/j.1540-4560.1963.tb00447.x]

[19] Bochner S, Lin A, McLeod BM. Cross-cultural contact and the development of an international perspective. J Soc Psychol 1979; 107(1): $29-41$.

[http://dx.doi.org/10.1080/00224545.1979.9922671]

[20] Kim YY. Becoming Intercultural An Integrative Theory of Communication \& CrossCultural Adaptation. Thousand Oaks, CA: Sage Publications 2001.

[21] Shabatura LN, Tarasova OV. Activity and adaptation of the person: methodological positions and praxeological meaning. Theory Pract Soc Dev 2015; 12: 320-2.

[22] Grigorieva MV. Ethno psychological specifics of adaptation activity and personal subjective well-being. Proc Univ Saratov Ser Philos Psychol Pedagogy 2012; 12(1): 49-53

[23] Panich OE. Ethno psychological methods of university foreign students' adaptation process accompany. Bulletin of Sholem Aleichem Amur State University 2011; 1(2): 54-62.

[24] Zimbardo PG, Boyd JN. Putting Time into Perspective. A Valid, Reliable individual-differences metric measurement J Pers Soc Psychol 1999; 77(6): 1271-88 [http://dx.doi.org/10.1037/0022-3514.77.6.1271]

[25] McLain DL. The MSTAT-I: A new measure of an individual's tolerance for ambiguity. Educ Psychol Meas 1993; 53(1): 183-9. [http://dx.doi.org/10.1177/0013164493053001020]

[26] Ryff CD, Keyes CLM. The structure of psychological well-being revisited. J Pers Soc Psychol 1995; 69(4): 719-27. [http://dx.doi.org/10.1037/0022-3514.69.4.719]

[27] Diener E, Emmons RA, Larsen RJ, Griffin S. The Satisfaction with Life Scale. J Pers Assess 1985; 49: 71-5. [http://dx.doi.org/10.1207/s15327752jpa4901_13]

[28] Rogers CR, Dymond RF, Eds. Psychotherapy and Personality Change: Coordinated Research Studies in the Client-Centered Approach. Chicago: University of Chicago Press 1954.

[29] Medovikova EA. The time perspective of the person with different level of self-conscious at certain stages of learning in high school. Probl Prospects Mod Sci 2015; 5: 64-9.

[30] Lykova NM, Lin Zh, Sheguan Y. Coping styles and meaning of life orientation among Chinese students in the period of adaptation to Russian and native university studying. Bulletin of Peoples' Friendship University of Russia. Ser: Psychol Pedagogy 2011; 3: 19-28.

C 2017 Tatiana S. Pilishvili

This is an open access article distributed under the terms of the Creative Commons Attribution 4.0 International Public License (CC-BY 4.0), a copy of which is available at: (https://creativecommons.org/licenses/by/4.0/legalcode). This license permits unrestricted use, distribution, and reproduction in any medium, provided the original author and source are credited. 